\title{
H-Bridge Configuration for Wide Range Speed Control of DC Motor
}

\author{
Vinayak .S.W ${ }^{1}$, K. M. Kavitha ${ }^{2}$ \\ ${ }^{1}$ Student, Electrical and Electronics Engineering Dept, AIT College, Chikkamagaluru-577102 Karnataka, India \\ ${ }^{2}$ Adjunct Faculty, Electrical and Electronics Dept., AIT College, Chikkamagaluru-577102 Karnataka, India
}

\begin{abstract}
Majority of the industrial drives are AC drives, due to their robust construction, low power loss, low maintenance and simple starting arrangement. However, these motors are constant speed drives and do not allow smooth speed control over a wide range and operation in either direction. Direct current $(D C)$ motor has already become an important drive configuration for many applications across a wide range of powers and speeds. The ease of control and excellent performance of the DC motors will ensure that the number of applications using them will continue grow for the foreseeable future. To operate motor in either direction DC motor can be used because of its simplicity. Although conventional methods are available for speed control, modern high speed switching power devices have opened new area in this field. The major advantages of power electronic control of drives are compactness, flexibility and greater precision in speed control. A simple, cost effective and efficient method of controlling the speed of DC motor is to incorporate PWM control. Use of microcontroller reduces the control hardware, increases the reliability and brings in flexibility to the control scheme. To study the efficiency of such systems, in the present work it is planned to design and test PWM controlled H-Bridge Converter for DC motor. The design of converter, generation of PWM pulses and microcontroller programs developed in the present work are discussed in detail in this report.
\end{abstract}

Keywords: H-Bridge, PWM, DC motors, MOSFET, MICROCONTROLLER.

\section{Introduction}

One can look forward to an era where every application in the industry will be driven by highly efficient and reliable drives. Most of the drives used in the industries today are electrical. Electric drives are widely used in the industry because of high reliability and versatility of speed control. Speed control over a wide range in a very smooth manner is possible with the advent of modem power electronic devices such as POWER TRANSISTER, SCR, MOSFET etc. Optimization and automation have improved the static and dynamic behavior of these drives.

Motor control applications span everything from washing machines to fans, hand-held power tools, and automotive window lift and traction control systems. In most of these applications there is a move away from analog motor control to precision digital control of motors. Digital control of motors permits a much more efficient operation of the motor, resulting in longer life, lower power dissipation, and a lower overall system cost. The most common expectation from any industrial drive is precise control ofspeed and torque, position with long-term stability, good transientperformance and high efficiency.

Modern technology offers various alternatives in the selection of drive system. Depending on the application, some of them are fixed speed and some of them are variable speed. The variable speed drives, till a couple of decades back, had various limitations such as poor efficiency, larger space requirement, lower speeds etc. However, the advent of power electronics transformed the scene completely. Today variable drive systems are smaller in size but also very efficient, highly reliable and meet all the stringent demands of various industries of modem era.

\section{Objectives}

1) To design and implement $\mathrm{H}$-Bridge configuration for DC drive.

2) To control speed of separately excited DC motor in either direction using H-Bridge configuration.

\section{Methodology}

To control speed of DC motor in either direction using microcontroller involves various stages and use of various components. The procedure of integrating different stages is explained below.

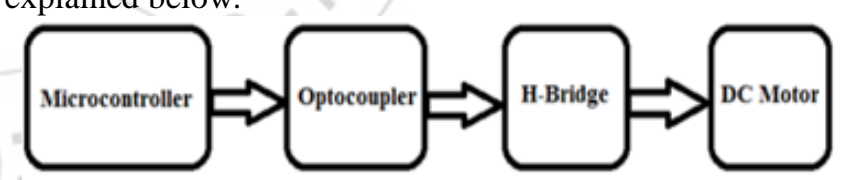

Figure 1: Block diagram

\subsection{Microcontroller}

A microcontroller (sometimes abbreviated $\mu \mathrm{C}, \mathrm{uC}$ or $\mathrm{MCU}$ ) is a small computer on a single integrated circuit containing a processor core, memory, and programmable input/output peripherals. Program memory in the form of NOR flash or OTP ROM is also often included on chip, as well as a typically small amount of RAM. Microcontrollers are designed for embedded applications, in contrast to the microprocessors used in personal computers or other general purpose applications. Voltage transients with speeds up to $10 \mathrm{kV} / \mu \mathrm{s}$. A common type of opto-isolator consists of an LED and a phototransistor in the same package. Optoisolators are usually used for transmission of digital (on/off) signals, but some techniques allow use with analog (proportional) signals. 


\section{International Journal of Science and Research (IJSR)}

ISSN (Online): 2319-7064

Index Copernicus Value (2013): 6.14 | Impact Factor (2015): 6.391

\subsection{OPTO-COUPLER}

Opto-coupler MCT2E consists of a gallium arsenide infrared emitting diode driving a silicon phototransistor in a 6-pin dual in-line package.

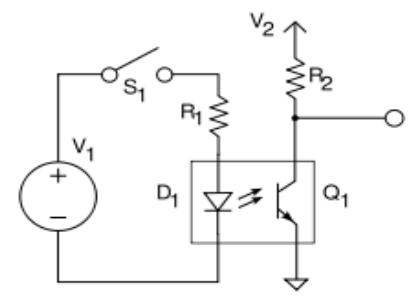

Figure 2: Circuit which is used for gate drive.

In the above circuit the voltage $V_{1}$ is the output of microcontroller pulse. This is used when data need to be transferred from one subsystem to another without making a direct 'ohmic' electrical connection. Often this is because source and destination are (or may be at times) at very different voltage levels, like a microcontroller which is operating from $5 \mathrm{~V} \mathrm{DC}$, but being used to control a power equipment like MOSFET, SCR, Triacetc, which are switching from $240 \mathrm{~V}$ AC or DC. In such situations the link between the two must be an isolated one, to protect the microcontroller from over voltage damage. Relays can of course provide this kind of isolation, but even small relays tend to be fairly bulky compared with IC's and many of today's other miniature circuit components, because they are electromechanical in nature. Where small size, higher speed and greater reliability are important, a much better alternative is to use an opto-coupler.

This uses a beam of light to transmit the signals or data across an electrical barrier and achieve excellent isolation. Opto-coupler typically come in a small 6pin or 8pin IC package, but are essentially a combination of two distinct devices; an optical transmitter, typically a Gallium arsenide LED (Light Emitting Diode) and an optical receiver such as a phototransistor or light triggered diac. The two are separated by a transparent barrier which blocks any electrical current flow between the two, but does allow the passage of light .Opto-coupler are essentially digital or switching devices, so they are best for transferring either onoff control signals or digital data. Analog signals can be transferred by means of frequency or pulse width modulation. The MCT2E is a NPN Silicon planar photo transistor optically coupled to a gallium arsenide infrared emitting diode.

\subsection{H-Bridge}

In general an H-bridge figure is a rather simple circuit, containing four switching element, with the load at the centre in an H-like configuration.

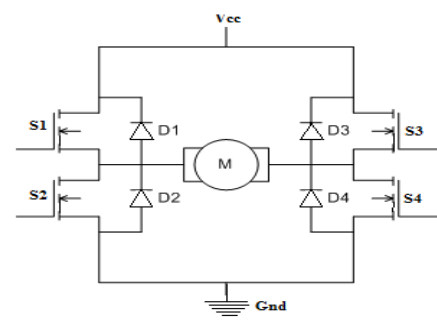

Figure 3: H-Bridge Circuit

MOSFET are used as power switches which are indicated as $\mathrm{S} 1, \mathrm{~S} 2, \mathrm{~S} 3$ and S4 in the circuit. The diodes (D1, D2, D3 and D4) are usually of a Schottky type. The basic operating mode of an H-bridge is fairly simple: if S2 and S3 are turned on, the left lead of the motor will be connected to ground, while the right lead is connected to the power supply. Current starts flowing through the motor which energizes the motor in (let's say) the forward direction and the motor shaft starts spinning. If $\mathrm{S} 1$ and $\mathrm{S} 4$ are turned on, the converse will happen, the motor gets energized in the reverse direction, and the shaft will start spinning in that way. If less than full-speed (or torque) operation is intended one of the switches are controlled in a PWM fashion. The average voltage seen by the motor will be determined by the ratio between the 'on' and 'off' time of the PWM signal.

\subsection{Motor.}

A DC motor is an electric motor that runs on DC electricity. It works on the principle of electromagnetism. A current carrying conductor when placed in an external magnetic field will experience a force proportional to the current in the conductor. This H-Bridge technique can be used for both shunt type and separately excited DC motor. We are using Separately excited DC Motor of 220V, 2.3 A, 1500 RPM.

\section{Data Flow Diagram of Reset}

A. Initialize the program to set the duty cycle for $10 \%$ and clockwise for 1 and counter clockwise (CCW) for 0 .

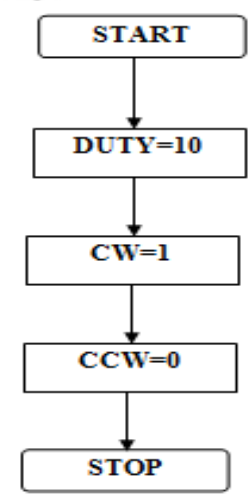

Figure 4: Data Flow Diagram of Reset.

\section{B. Data Flow Diagram of Increment or Decrement of Duty Cycle.}

Initially as per reset, duty cycle will be set to $10 \%, \mathrm{CW}$ will be set to 1 and $\mathrm{CCW}$ will be set to 0 . Then check whether duty cycle is less than $100 \%$ if not then go to stop, if yes check whether $\mathrm{CW}$ is set to 1 . If it is 1 then increment duty 


\section{International Journal of Science and Research (IJSR) \\ ISSN (Online): 2319-7064}

Index Copernicus Value (2013): 6.14 | Impact Factor (2015): 6.391

cycle by $10 \%$ for each step upto $100 \%$. If $\mathrm{CW}$ is not equal to 1 , then CCW will be 1 then increment duty cycle by $10 \%$ for each step upto $100 \%$. If duty cycle is more than $100 \%$ stop the program.

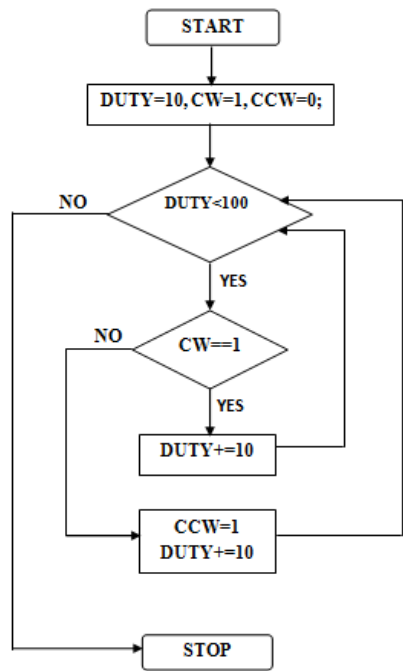

Figure 5: Data Flow Diagram of Increment or Decrement of Duty Cycle

\section{Result}

H-Bridge Setup with Resistive Load:

Experiments were conducted to find the influence of $\mathrm{M}$, number of pulses on the output voltage of the H-Bridge. The result sheet consists of two types of outputs.

1) Output in forward direction for different duty cycles.

2) Output in reverse direction for different duty cycles.

In all these cases, DC input was maintained constant. HBridge converter was rigged up and tested for our convenience. The H-Bridge converter is tested with $20 \mathrm{~V}$ DC supply with rheostat of 5A. Experimental setup used for resistive load is as shown in figures.

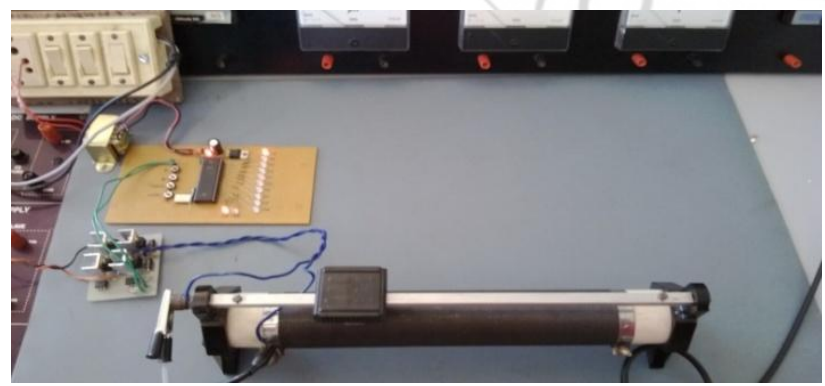

Figure 6: Experimental Setup for Resistive Load

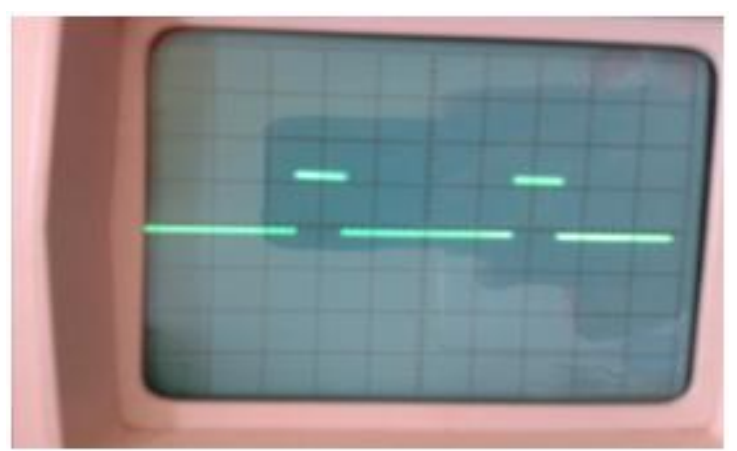

Figure 7: Microcontroller output for $20 \%$ duty cycle.

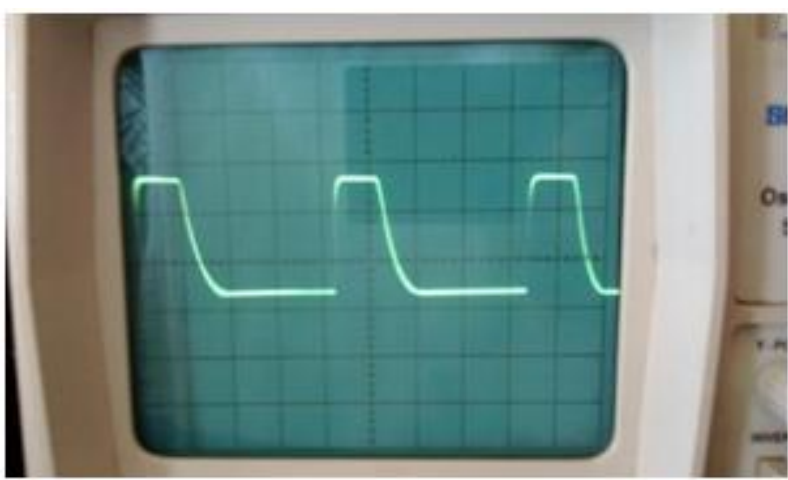

Figure 8: H-Bridge output across rheostat for $20 \%$ duty cycle in forward direction when S1 and S4 Conducting.

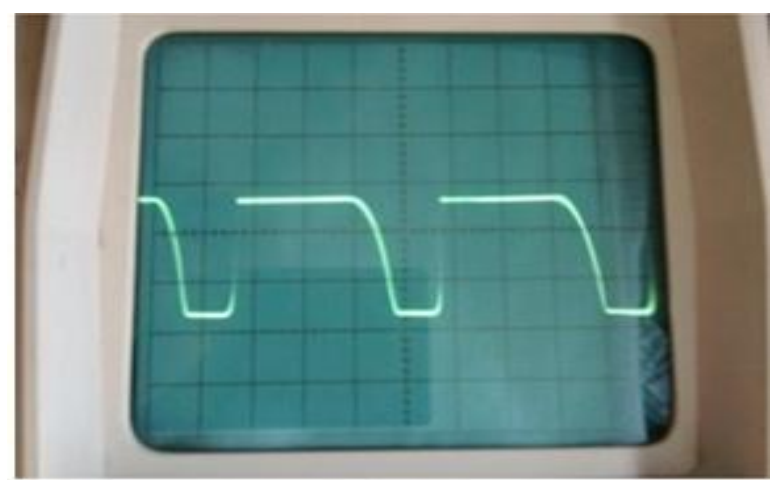

Figure 9: H-Bridge output across rheostat for $20 \%$ duty cycle in reverse direction when S3 and S2 Conducting.

Table 1: Speed and Duty Cycle in Forward Direction

\begin{tabular}{|c|c|}
\hline Duty Cycle in \% & Speed in rpm \\
\cline { 2 - 2 } & Forward Direction \\
\hline 10 & 82 \\
\hline 20 & 159 \\
\hline 30 & 220 \\
\hline 40 & 260 \\
\hline 50 & 295 \\
\hline 60 & 311 \\
\hline
\end{tabular}

Table 2: Speed and Duty Cycle in Reverse Direction

\begin{tabular}{|c|c|}
\hline Duty Cycle in \% & Speed in rpm \\
\cline { 2 - 2 } & Reverse Direction \\
\hline 10 & 73 \\
\hline 20 & 151 \\
\hline 30 & 224 \\
\hline 40 & 266 \\
\hline 50 & 295 \\
\hline 60 & 314 \\
\hline
\end{tabular}




\section{International Journal of Science and Research (IJSR) \\ ISSN (Online): 2319-7064}

Index Copernicus Value (2013): 6.14 | Impact Factor (2015): 6.391

Table 1 and Table 2 shows the speed and duty cycle in forward and reverse direction of DC motor it can be observed that the speed of the DC motor was increasing with increase in the duty cycles and characteristic of the DC motor was found to be same in forward and reverse direction.

\section{Conclusion}

To run and control the motor in both forward and reverse with a processor, we need more circuitry. H-Bridge circuit is a popular circuit for driving DC motors. The great ability of an H-Bridge circuit is that the motor can be driven forward or backward at any speed, optionally using a completely independent power source. The H-Bridge design can be really simple for prototyping or really extravagant for added protection and isolation.

The present work is mainly focused on generating PWM of H-Bridge Bridge with different pulse input at the gates of MOSFET. We have checked and confirmed the results by giving pulse for resistive load and a DC motor. In this project the experiments conducted for universal motor. A comparison can be done between the present MOSFET module and other power semiconductor device modules to get best out of the two.

\section{Future Work}

A comparison can be done between the present MOSFET module and other power semiconductor device modules to get best out of the two. With the efficient use of the same microcontroller, the feedback can be taken out from motor to run it at constant speed or at desired speed.

A comparison can be done between the present MOSFET module and other power semiconductor device modules that could be IGBT based .Using IGBT switches with proper design of the circuit it is possible that it can be adapted to higher rating devices. And it is possible to implement the present circuit on shunt motors, this can be achieved by making appropriate changes in the circuit which can visualized as the further step in the improvement of the present circuit.

\section{References}

[1] "Electrical Machine Design" By A.K.SawhneyDhanpatRai and CompaqnySixthEdition 2010.

[2] “Control System" by. Ogata

[3] "Power Electronics circuits, devices, and applications" second edition. Muhammad M Rashid.

[4] "Industrial Drives and Application" G.K.Dubey

[5] Journal from Mohd. Amir Fikri Bin Awang , November 2010

[6] "Power electronics". khanna publishers. $\operatorname{Dr} P S$ Bimbhra

[7] "Ellectrical Technology Vol.2 AC and DC Machines" B.L. Theraja and A.K.Theraja.

[8] "Electric Machines", KhannaPublisers. AshfaqHussain
[9] "The 8052 Microcontroller Architecture, programming, \& Applications. second edition" Kenneth J Ayala Penram International Publishing(I) Pvt. Ltd.

[10] "The 8051 Microcontroller and Embedded Systems" Pearson Prentice Hall . Muhammad Ali Mazidi and Janice GillispieMazidi

[11] "Microprocessor Architecture, Programming and Applications with the 8085"fifth edition. Ramesh GaonkarPenram International Publishing(I) Pvt. Ltd.

[12] "Electric Drives Concepts and Applications" Tata McGraw Hill publications. VedamSubramanyam.

[13] 8052 Microcontrollers Arcitectural Overview User's Manual

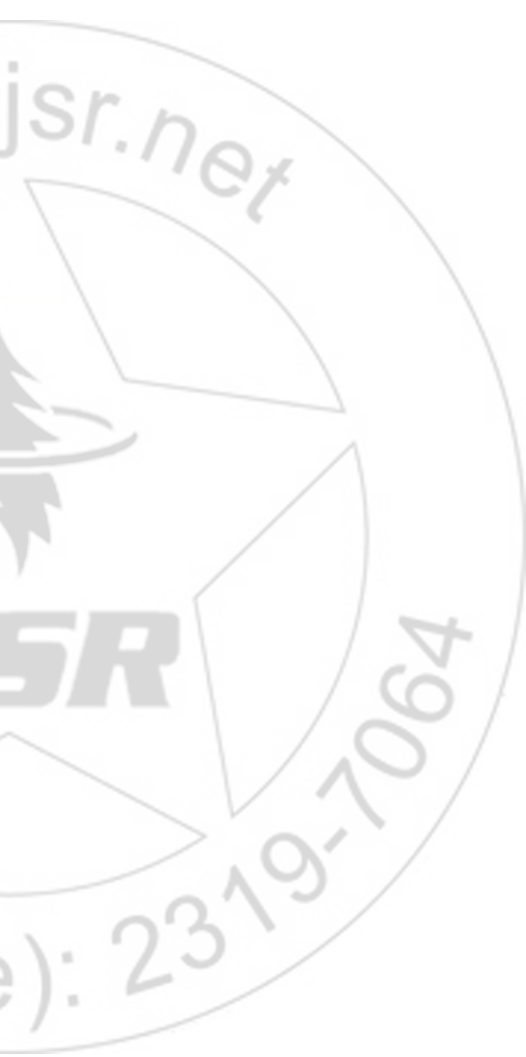

